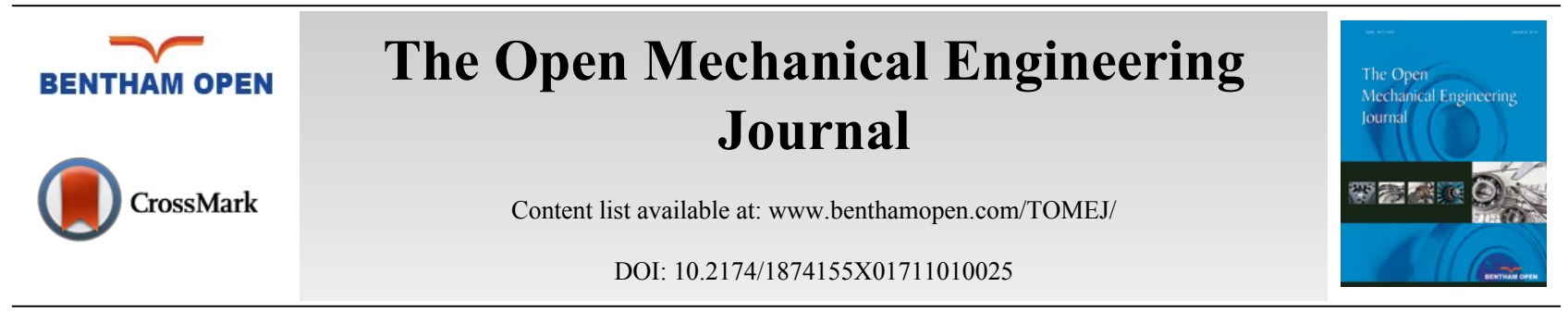

RESEARCH ARTICLE

\title{
Drilling Mechanism Investigation on SiC Ceramic Using Diamond Bits
}

\author{
Chao Gao*, Guorong Wu and Sheng Wang \\ Department of Mechanical Engineering, Jiangsu University of Science and Technology, Zhenjiang 212000, China
}

Received: December 20, 2016

Revised: March 03, 2017

Accepted: April 03, 2017

\begin{abstract}
:
Background:

$\mathrm{SiC}$ ceramic have been widely used in the fields of armor protection, but SiC ceramic is one of the difficult-to-machine material for its high hardness and low fracture toughness.
\end{abstract}

\section{Objective:}

This paper presents an investigation of drilling mechanism on SiC ceramic using diamond bits.

\section{Method:}

Based on the theory of indentation fracture mechanics model, cutting average load model and cutting average depth model for single particle were established, theory analysis of drilling mechanism was carried out; through scanning electron microscope (SEM) observation, experimental removal mechanism was discussed.

\section{Results and Conclusions:}

The results show that, brittle fracture is the dominant way for SiC ceramic's removal mechanism, plastic deformation always exists during the drilling process. Brittle fracture includes cleavage fracture, transgranular fracture, intergranular fracture, material peeling off and grain boundary breakage; resintering and recrystallization happen under the joint action of grinding forces and grinding heat in the contact area, where plastic flow characteristics also appear; powdering removal is accompanied by the drilling process; cleavage fracture and transgranular fracture occur on intergranular pores and grain boundary; residual cracks are found in the drilling surface resulted by drilling stress and high temperature.

Keywords: SiC ceramic, Drilling mechanism, Diamond bits, Brittle fracture, Plastic deformation, Powdering cracks.

\section{INTRODUCTION}

$\mathrm{SiC}$ ceramics have been widely used in the fields of national defense, new energy, aerospace, automotive, medical etc. for its excellent physical and mechanical properties such as high hardness, high strength, high temperature resistant and corrosion resistant [1 - 3]. Ceramic often needs secondary processes during assembling process such as drilling, slotting etc.. However, $\mathrm{SiC}$ ceramic is one of the difficult-to-machine materials for its high hardness and low fracture toughness, which have limited the uses. Currently, lots of efforts were made on SiC ceramic's processing. L. F. Liu et al. [4] analyzed the SiC grinding mechanism using ultrasonic vibration which indicated brittleness removal was the dominant way. Y. T. Dai et al. [5] studied grinding surface properties of SiC ceramic using grinding wheels of different abrasive sizes, binders and shapes and discussed the forming mechanism of grinding surface. Y. L. Zhang [6] analyzed the effect of the SiC ceramic grinding parameters on grinding efficiency, surface roughness and surface topography.

\footnotetext{
* Address correspondence to this author at the Department of Mechanical Engineering, Jiangsu University of Science and Technology, Zhenjiang, China; Tel: +86 18651405721; E-mail: gaochaozibo@qq.com
} 
X. J. Tang et al. [7] studied the marginal rupture phenomenon of engineering ceramics in the grinding process and analyzed the mechanism of marginal rupture. Z. B. Wang et al. [8] used carved computer numerical control machine tool to drill $\mathrm{SiC}$ ceramic, and obtained the efficient and reasonable grinding processing of engineering ceramic. G. $Z$. Xie et al. [9] studied the influence of linear velocities, grinding depths and material removal way of ceramic using grinding wheel. J. X. Zheng et al. [10] established ductile grinding model of ceramic material and discussed its grinding mechanism under conditions of ultrasonic grinding. W. Yao et al. [11] studied ceramic surface morphology, residual stress etc. using diamond grinding wheel. J. M. Ni et al. [12] studied the grinding characteristics of SiC ceramic and presented the compound mode. Sanjay Agarwal et al. [13] studied surface morphology and material removal way of $\mathrm{SiC}$ ceramic using diamond grinding wheel to grind $\mathrm{SiC}$ ceramic. R. J. Ji et al. [14] studied the influence of processing conditions on $\mathrm{SiC}$ ceramic material removal rate, electrode wear and surface quality. J. G. Cao et al. [15] analyzed material removal mechanism by simulation and experiment process when processing SiC ceramic using ultrasonic assisted grinding method. J. Xie et al. [16] established a cutting depth model and analyzed micro brittle cracks when grinding SiC ceramic used elliptic diamond grinding wheel. K. Zhang et al. [17] studied the material removal mechanism using single-layer brazing diamond grinding wheel to grind $\mathrm{SiC}$ ceramic. However, the above researches only involve removal ways of plane and surface of revolution, rare works are found in drilling, and theoretical analysis is almost not involved. In this paper, mathematical model of single abrasive average cutting load and single abrasive average cutting depth are analyzed and ceramic grinding surface morphology for drilling is discussed further by SEM. The research is helpful to promote processing technology and improve drilling quality.

\section{MATERIALS AND METHODS}

Hot pressing sintering diamond bits and electroplated diamond bits were used in the experiment. The structure of sintering diamond bit is shown in Fig. (1), which is composed of working layer, transition layer and basal body. Working layer is made by diamond abrasives and metal bond through hot pressed sintering in which diamonds disperse in bonds randomly; transition layer is used to connect working layer and basal body which is composed of binder powder; basal body is made by 45 \# steel. The binder composition is Cu50Co25Sn18Ti7 (wt\%), sintering temperature is $600{ }^{\circ} \mathrm{C}$, sintering pressure is $14.7 \mathrm{MPa}$ and the holding time is $2 \mathrm{~min}$. For the dimensions of sintering diamond bits, working layer height is $6 \mathrm{~mm}$, wall thickness is $2 \mathrm{~mm}$, outside diameter is $20 \mathrm{~mm}$, number of nozzles is 2 , diamond grit (Type: SMD40, Supplier: NanJing LiDe Abrasives Co., Ltd.), whose compressive strength is 352.80 N, TI (toughness index) is $75 \%$, TTI (thermal toughness index) is $68 \%$, size is $50 / 60$ US mesh $(300-250 \mu \mathrm{m})$ and diamond concentration is $50 \%\left(0.44 \mathrm{~g} / \mathrm{cm}^{3}, 400 \%\right)$. The structure of electroplated diamond bit is shown in Fig. (2), its outside diameter is 20 $\mathrm{mm}$, working layer height is $4 \mathrm{~mm}$, diamond grit size is $50 / 60$ US mesh $(300-250 \mu \mathrm{m})$ and diamond abrasive concentration is $200 \%\left(1.76 \mathrm{~g} / \mathrm{cm}^{3}\right)$.

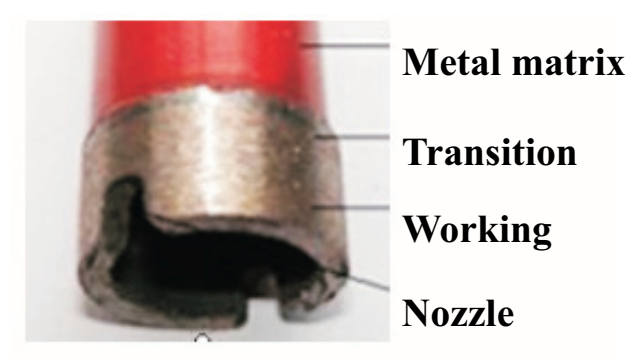

Fig. (1). Sintering diamond bit.

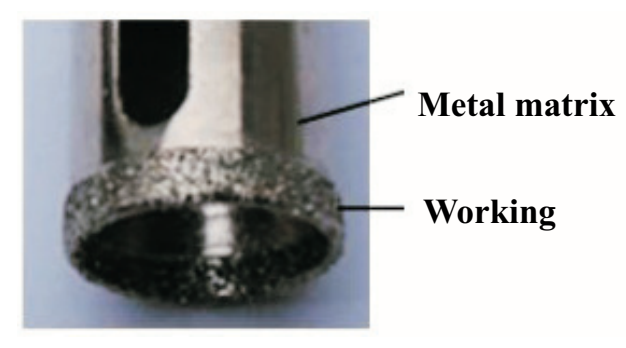

Fig. (2). Electroplated diamond bit. 
$\mathrm{SiC}$ ceramic ( $99.5 \mathrm{wt} \%$ ) used in the experiment is $10 \mathrm{~mm}$ in thickness, density is $3.28 \mathrm{~g} / \mathrm{cm}^{3}$, fracture toughness is $3.9 \mathrm{MPa} \cdot \mathrm{m}^{1 / 2}$, vickers hardness is $26 \mathrm{GPa}$, modulus of elasticity is $430 \mathrm{GPa}$, flexural strength is $580 \mathrm{MPa}\left(25^{\circ} \mathrm{C}\right)$, which is shown in Fig. (3).

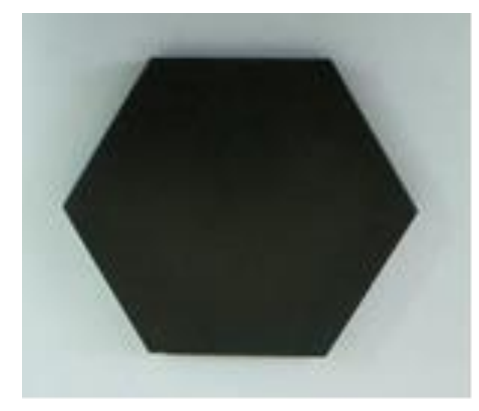

Fig. (3). SiC ceramic.

The experiment was carried out on ZXL-20 drilling milling machine whose rated power is $750 \mathrm{~W}$, spindle speed of 1800 RPM, 2600 RPM and 3200 RPM were available. Constant feeding pressure of 695 N, 735 N, 795 N, 835 N was adopted, which was achieved by applying weights $(9 \mathrm{~kg}, 10 \mathrm{~kg}, 11 \mathrm{~kg}, 12 \mathrm{~kg}$ respectively) on the drilling milling machine. Pure water cooling was used during the experiment to reduce the temperature on grinding surface, whose cooling fluid pressure was $0.3 \mathrm{MPa}$, cooling fluid flow was $120 \mathrm{cc} / \mathrm{s}$. JMS-6300 scanning electron microscope was used to observe the grinding surface. Gold was sprayed in grinding surface before observation to ensure its electrical conductivity.

The experiments setup is shown in Fig. (4).

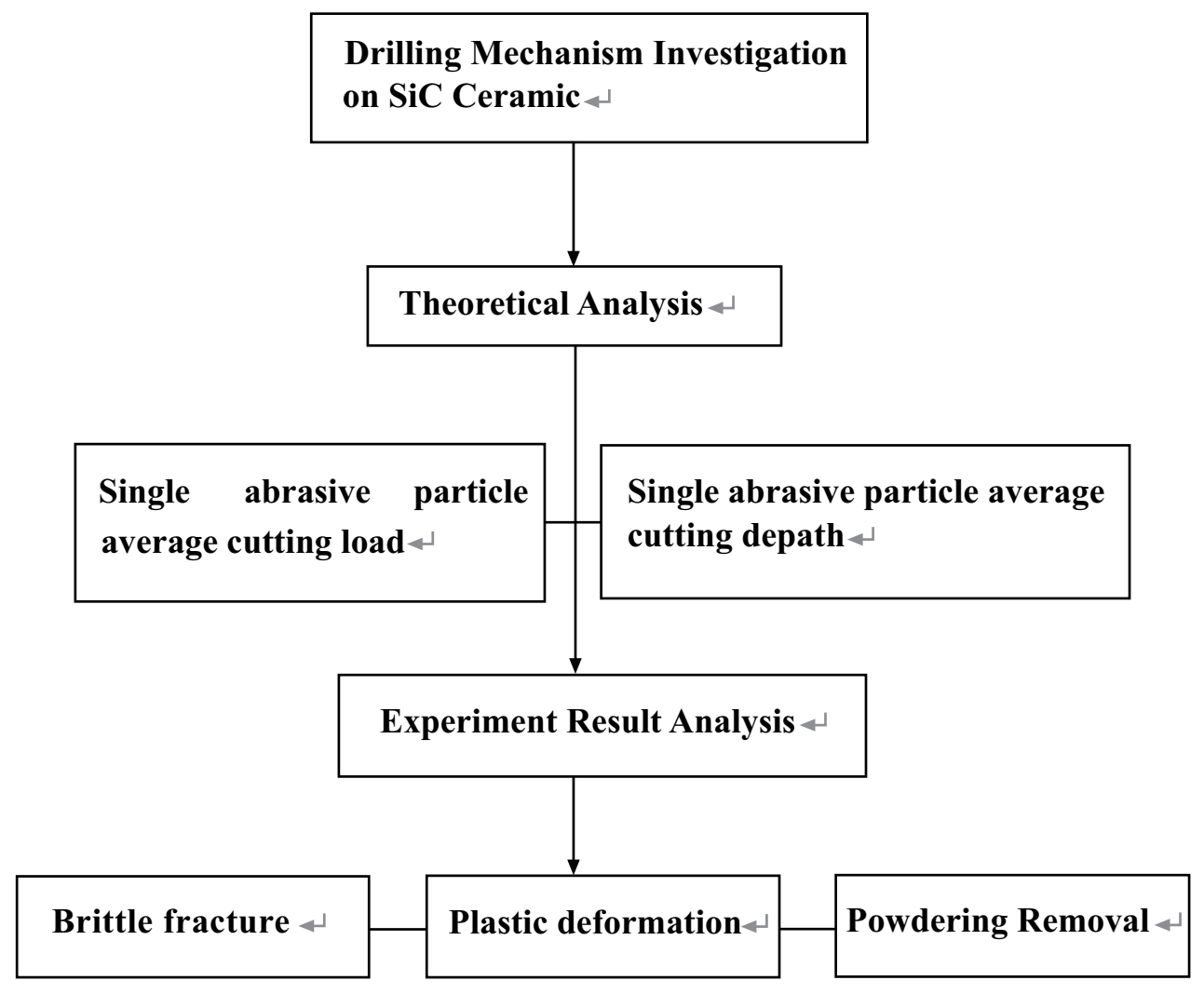

Fig. (4). Experiments setup. 


\section{RESULTS AND DISCUSSION}

\subsection{Theoretical Analysis}

According to the indentation fracture mechanics model [18], when normal load of single abrasive particle is greater than a certain critical load, cracks will be produced on ceramic surface, and brittle fracture occurs when cracks extend to free surface; when normal load of single abrasive particle is smaller than the certain critical load, cracks will not be produced, there is only plastic deformation on the material surface caused by the friction of abrasive particles. Therefore, $\mathrm{SiC}$ ceramic removal mechanisms can be judged by calculating single abrasive particle average cutting load and single abrasive particle average cutting depth.

\subsubsection{Single Abrasive Particle Average Cutting Load}

Assume diamond abrasive particles are regular spheres, the number of diamond particles in $1 \mathrm{~cm}^{3}$ unit volume working layer is set as $n_{v}$,

$$
n_{v}=1000 \frac{0.25 C}{\left(\pi d^{3} / 6\right)}=\frac{1500 C}{\pi d^{3}}
$$

Among them: $C$ is the diamond concentration (volume percent, $400 \%$ concentration), $d(\mu \mathrm{m})$ is average diameter of diamond particles.

Diamond particles will fall off with the wear of matrix in the process, the proportion of the biggest exposed height to diamond particle diameter is set as $k$, the literature [19] shows that the exposed height of diamond particle on matrix surface does not exceed one-third of particle diameter, i.e., $k \leq 30 \%$. Diamond particles are not in the same layer microscopically [20,21], the number of diamond particle layers in $1 \mathrm{~cm}^{3}$ unit volume is set as $m_{\mathrm{v}}$, so

$$
m_{v}=\frac{10}{k d}
$$

The number of exposed diamond particles in $1 \mathrm{~cm}^{2}$ unit area on the working surface is set as $N_{0}$ :

$$
N_{0}=\frac{n_{v}}{m_{v}}=\frac{150 C k}{\pi d^{2}}
$$

Since exposed diamond particles are not working at the same time in the processing, working diamond particles account for $\xi$ of exposed diamond particles, according to the literature [22], $\xi \leq 26 \%$. So the number $N_{\xi}$ of working diamond particles in $1 \mathrm{~cm}^{2}$ unit area is:

$$
N_{\zeta}=\zeta N_{0}
$$

The average load $\bar{p}(\mathrm{~N})$ of single diamond abrasive particle on the working surface can be represented as:

$$
\bar{p}=\frac{P_{0}}{N_{\xi}}=\frac{\pi d^{2} P_{0}}{150 C k \xi}
$$

Among them: $P_{0}(\mathrm{~N})$ is the axial feed load in $1 \mathrm{~cm}^{2}$ unit area on the working surface.

If the axial feed load which is applied on the working surface is set as $P(\mathrm{~N})$, so $P_{0}$ can be represented as [18]:

$$
P_{0}=\frac{P}{S}=\frac{P}{\pi\left(D^{2}-d^{2}\right) / 4-n b(D-d) / 2}
$$

Among them: $n$ is the number of rectangular nozzles of the bit, $b(\mathrm{~cm})$ is the width of the nozzle, $D(\mathrm{~cm})$ and $d(\mathrm{~cm})$ 
are the outer diameter and inner diameter of the diamond bit respectively, $S\left(\mathrm{~cm}^{2}\right)$ is the total area of the bit working surface.

\subsubsection{Single Abrasive Particle Average Cutting Depth}

Single abrasive particle average cutting depth $\bar{a}_{\mathrm{g}}(\mu \mathrm{m})$ on each cutting line of diamond bit can be represented as [18]:

$$
\bar{a}_{g}=\frac{H}{(2 \pi \rho-N b) m_{\xi}}
$$

Among them: $(\mu \mathrm{m})$ is cutting depth of each turn of the bit, $\rho(\mathrm{mm})$ is the radius of random circle on the bit surface, $m_{\xi}$ is the number of working diamond particles in $1 \mathrm{~cm}$ unit length on the bit surface, $m_{\xi}$ can be represented as:

$$
m_{\xi}=\frac{1}{\sqrt{N_{\xi}}}=d \sqrt{\frac{\pi}{150 c k \xi}}
$$

Under conditions of constant pressure feeding:

$$
H=\frac{L}{t n}
$$

Among them: $L(\mathrm{~mm})$ is the thickness of the workpiece material, $t(\mathrm{~s})$ is the drilling time of per-hole, $n(\mathrm{r} / \mathrm{min})$ is spindle speed.

When particles cutting ceramic, the instantaneous cutting depths of each abrasive particle are not equal. Single abrasive particle cutting depth increases gradually from zero and cutting depth decreases rapidly after reaching the biggest cutting depth [18]. The literature [23] about geometry analysis of abrasive particle cutting movement shows that the biggest cutting depth of single abrasive $\mathrm{a}_{\mathrm{gm}}(\mu \mathrm{m})$ is two times (the biggest undeformed chip thickness) longer than average cutting depth $\bar{a}_{\mathrm{g}}(\mu \mathrm{m})$, so $\mathrm{a}_{\mathrm{gm}}$ can be represented as:

$$
a_{g m}=2 \bar{a}_{g}=\frac{2 H}{(2 \pi \rho-N b) m_{\xi}}
$$

Under the experimental conditions, drilling time of per-hole (ceramic is $10 \mathrm{~mm}$ in thickness) is $21 \sim 35 \mathrm{~s}$, the axial pressure is more than $695 \mathrm{~N}$ in general and the maximum spindle speed is $3200 \mathrm{r} / \mathrm{min}$. According to the above parameters, take the parameter values, which make cutting depth $\mathrm{a}_{\mathrm{gm}}(\mu \mathrm{m})$ get the minimum. With combining formula (5) and (10), single abrasive average cutting load $\bar{p}$ of $23.6 \mathrm{~N}$ and the minimum of the cutting depth $\mathrm{a}_{\mathrm{gm}}$ of $8.52 \mu \mathrm{m}$ can be obtained.

According to the indentation fracture mechanics model, the minimum of single abrasive particle critical load which produces cracks can be represented as $P_{l}^{*}(\mathrm{~N})[24]$ :

$$
P_{l}^{*}=\zeta\left(\frac{K_{c}}{H}\right)^{3} K_{c} f(E / H)
$$

Among them: $\zeta$ is a dimensionless parameter, $f(E / H)$ is an attenuation function, $f(E / H) \approx 2 \times 10^{5}$ in this paper.

Critical cutting depth of single abrasive particle is determined by the minimum of single abrasive particle critical load, so critical cutting depth of single abrasive particle $\mathrm{a}_{\mathrm{gc}}(\mu \mathrm{m})$ can be represented as: 


$$
a_{g c}=\left(\frac{K_{c}}{H}\right)^{2}\left(\frac{\lambda_{0}}{\zeta}\right)^{1 / 2} \frac{1}{\tan \theta}
$$

Among them: $\lambda_{0}$ is a coefficient which is determined by the indentation fracture experiment of ceramic material and its value is in the range of 13500 to 20000; $\varsigma$ is geometric factor of abrasive particles and its value is 2 for ordinary Vickers indenter; $2 \theta$ is tip angle of abrasive particle cutting part; $K_{c}\left(\mathrm{MPa} \cdot \mathrm{m}^{1 / 2}\right)$ is fracture toughness of ceramic material; $H(\mathrm{GPa})$ is Vickers hardness of ceramic material.

For $\mathrm{SiC}$ ceramics $(99.5 \mathrm{wt} \%)$, its fracture toughness is $3.9 \mathrm{MPa} \cdot \mathrm{m}^{1 / 2}$, Vickers hardness is $26 \mathrm{GPa}$, single abrasive particle critical load $P^{*}{ }_{l}$ of $2.63 \mathrm{~N}$ can be obtained by formula (11) and single abrasive particle critical cutting depth $\mathrm{a}_{\mathrm{gc}}$ of $1.58 \mu \mathrm{m}$ can be obtained by formula (12) when $\lambda_{0}=20000$ and $\theta=55_{\circ}^{\circ}$.

It can be found that average cutting load and the minimum of the biggest cutting depth of single abrasive particle are far greater than critical cutting load and critical cutting depth of $\mathrm{SiC}$ ceramic under the experimental conditions, so brittle fracture is the most dominant removal way for $\mathrm{SiC}$ ceramic.

In addition, plastic deformation always exists during drilling process. This is because on the one hand, although the micro hardness of diamond (98.59 GPa, 50/60 US mesh) are much higher than that of SiC, there still are large amounts of alternating thermal stress and mechanical stress caused by periodic strong impact, extrusion and friction of diamond abrasives on ceramic, diamond grits appear partial micro-breakage, wear flatten and even large area breakage under the action of constant wear of the stress, the contact area increases, average cutting load of single abrasive particle decreases, when average cutting load of single abrasive particle is smaller than critical cutting load of $\mathrm{SiC}$ ceramic, material appears plastic deformation. On the other hand, material removal is caused by multiple abrasives, due to sharp blunt state and exposed height of abrasive particles being different, the actual cutting depths of abrasive particles are not equal, when the actual cutting depth of single abrasive particle is greater than the critical cutting depth, brittle fracture appears; otherwise, plastic deformation appears.

\subsection{Experiment Result Analysis}

Grooves and scratches with different length caused by plastic deformation and pits caused by brittle fracture damage can be found on the drilling surface by scanning electron microscope, which are shown in Fig. (5).

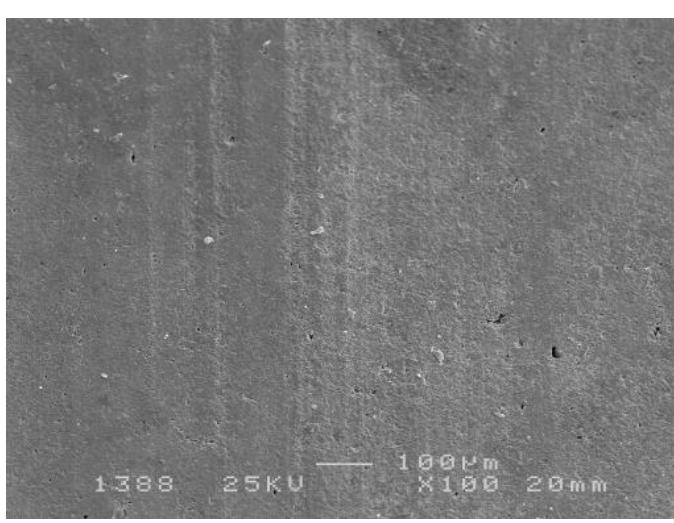

(a) $\times 100$

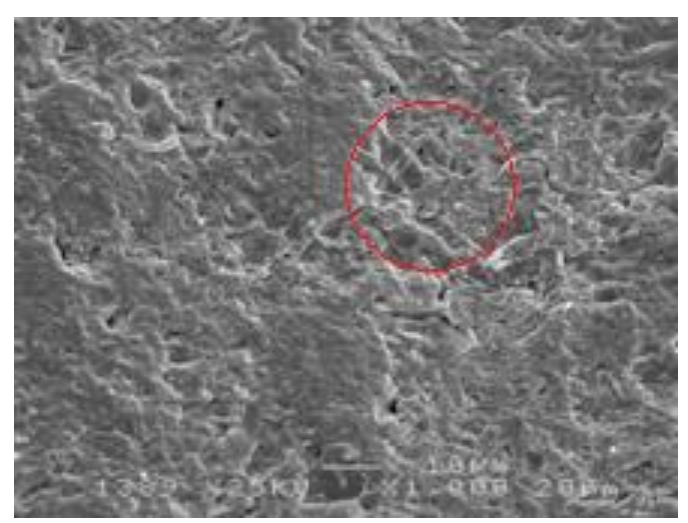

(b) $\times 1000$

Fig. (5). Drilling surface of SiC ceramic.

\subsubsection{Brittle Fracture Removal of SiC Ceramic}

The number of pits on the drilling surface is the largest which shows that brittle fracture is the dominant removal manner. A large number of crystalline grains and crystalline grain blocks fell off from the drilling surface in the form of cutting chips and formed pits under the action of drilling and impact load [25], as shown in Fig. (5). The removal way of brittle fracture mainly includes cleavage fracture, transgranular fracture, intergranular fracture, material peeling off and grain boundary micro-breakage of crystalline grains, as shown in Fig. (6). Cleavage fracture is a kind of 
transgranular fracture under the action of normal stress, which is because cracks extend along a certain crystal face (cleavage plane) at the beginning, when cracks cross the grain boundary, cracks start to extend along the crystal face whose direction is different from the previous and form cleavage. When cracks cross the crystalline grain and extend to the inside, transgranular fracture happens by the separation of slip planes which is caused by surface sliding, while transgranular fracture happens, cleavage fracture happens easily and produces cleavage steps. Intergranular fracture is produced by the brittle precipitate phase or inclusions existing in the grain boundary, besides, the high temperature environment and interaction of grain boundary can also cause the grain boundary weakening, which causes the whole crystalline grain peels off, and intergranular fracture occurs.

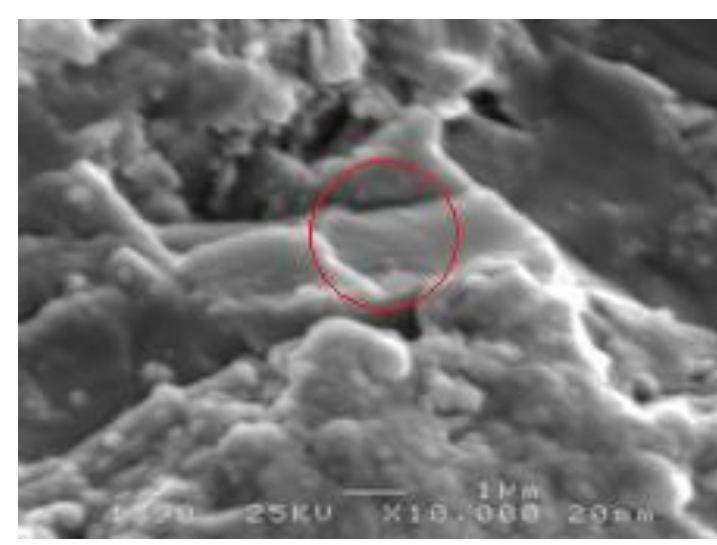

(a) Cleavage fracture and transgranular fracture

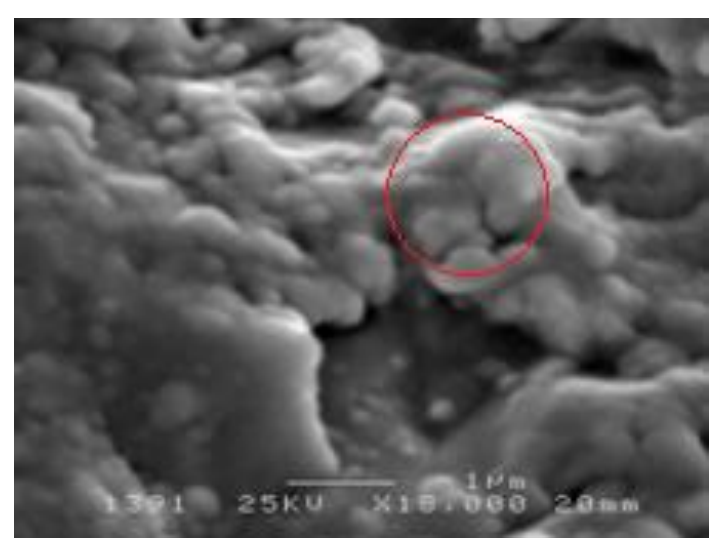

(b) Intergranular fracture

Fig. (6). Brittle fracture form of SiC ceramic.

The spalling of material is macroscopic manifestation of cleavage fracture, transgranular fracture and intergranular fracture, which are caused by the continuous expansion of transverse crackle and radial crackle.

Grain boundary micro-breakage is caused by continuous cracks which are formed under the action of circumferential stress and shear stress on the front surface of abrasives. Grain boundary micro-breakage leads to grain shape dislocation movement and internal micro-breakage of grains along with associative plane and slip plane of grain boundary, thus the removal of single or multiple crystalline grains is achieved.

\subsubsection{Plastic Deformation}

There are also a lot of grooves and scratches with different length, depth and width on the drilling surface, which indicate that the ceramic material is also removed by plastic deformation. Since the characteristics of drilling surface are the results of the combined action of many abrasive particles, the majority of scratches are discontinuous, as shown in Fig. (5). There exist irregular broken edges on both side of scratches.

The reasons are that with the expansion of cracks along with two sides and anterolateral sides of scratches under the action of squeezing of abrasive particle rake face, when cracks extend to free surface of scratches, ceramic material will appear brittle fracture and form irregular broken edges on both sides of scratches. Due to the expansion of cracks deeping into the interior of scratches, there also exist cracks and pits in the interior of scratches. There are many broken crystalline grains at the bottom and sides of scratches, some of the broken crystalline grains are separated from working face in the form of swarf, the other of them form dense crushed grain layer under the squeezing of diamond particles' facets.

Plastic characteristics on drilling surface are different when using different processing tools. The scratches with plastic flow characteristics produced by the electroplating diamond bit present more discontinuities. There are almost no long and complete scratches and the proportion of surface with plastic characteristic in total grinding surface is smaller as shown in Fig. (7), however, the scratches produced by sintering diamond bit appear more continuity, and the proportion of surface in total grinding surface is larger as shown in Fig. (8), the reason is that when feed pressure is determined, the wall thickness of electroplated diamond bit is thinner $(0.5 \mathrm{~mm})$, the number of diamond particles on the surface is smaller, so cutting load of single diamond particle is bigger and cutting depth is deeper, which make material to be removed in the form of brittle fracture mostly. 
Due to different exposed height and sharp blunt of abrasive particles, the process also accompanies plastic deformation, but the proportion of plastic cutting is small and the area of plastic feature is smaller. While drilling SiC ceramic using sintering diamond bit, because the wall thickness of sintering diamond bit is $1.5 \sim 2.5 \mathrm{~mm}$, which is thicker than that of electroplated diamond bit, its working surface is wider and the number of diamond particles is bigger, so the cutting load of single diamond particle is smaller and the cutting depth of single diamond particle is littler under the same feed pressure, then the possibility of plastic deformation is bigger.

In addition, abrasive particles of sintering diamond bit are easy to be dulled, and form a flat working surface, where cooling is not sufficient, thus the temperature on the drilling zone will be very high, which makes the ceramic fine powder easily be resintered and recrystallized under the extrusion of the working face, and a layer of plastic flow deformation zone is formed, as shown in Fig. (8). Since the flushing fluid reduces the temperature of the machining area, then reduces the possibility of resintered and recrystallized, the flushing fluid is needed to reduce the plastic flow deformation zone.

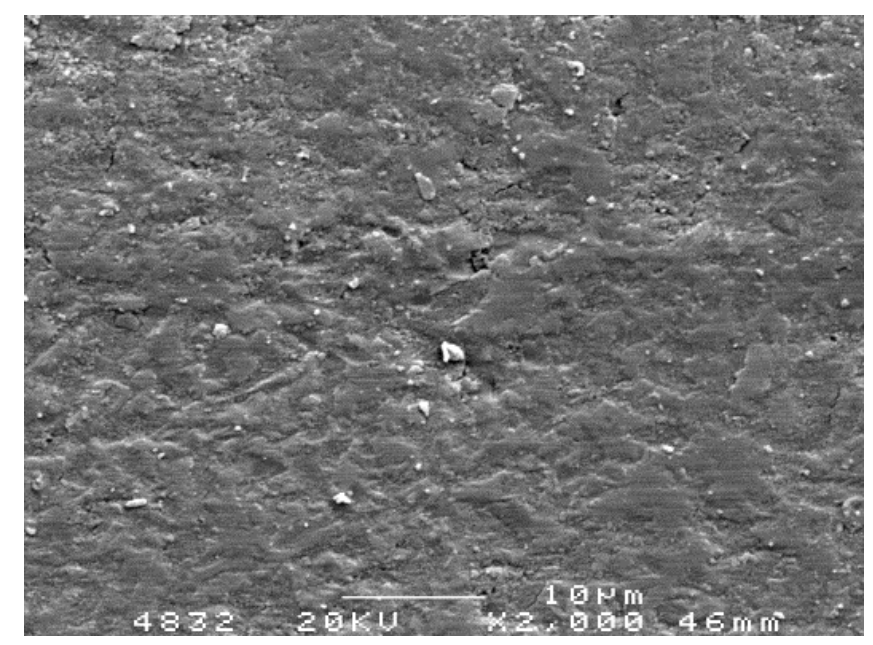

Fig. (7). Drilling surface using electroplated diamond bit.

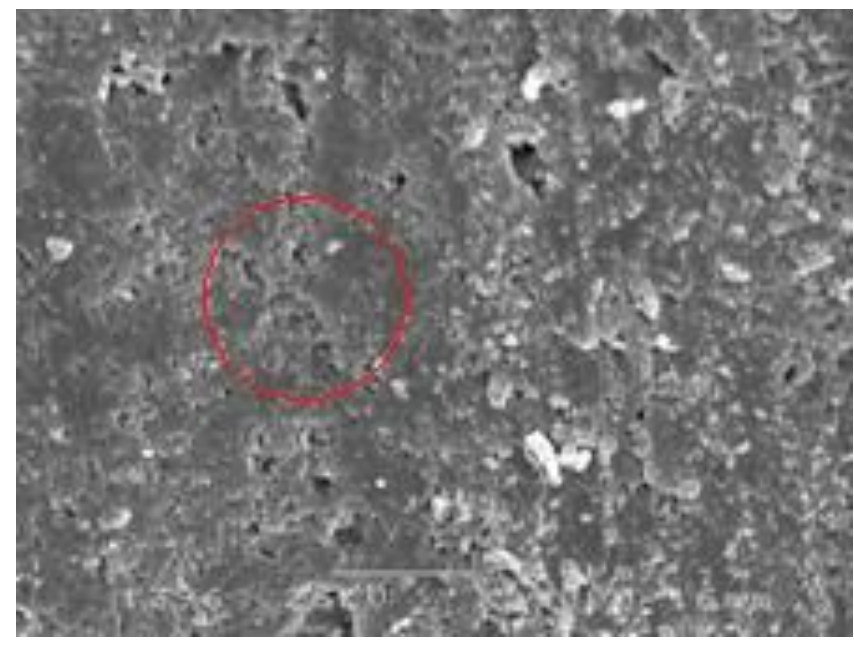

Fig. (8). Drilling surface using sintering diamond bit.

\subsubsection{Powdering Removal}

In the drilling of $\mathrm{SiC}$ ceramic, when the cutting depth of abrasive particles is among submicron grade, the micron sized ceramic powder will be generated along cleavage plane and slip system of crystalline grains. Grains are broken into smaller grains even powder, which are loosely bonded. Some of them are compacted under the action of hydrostatic stress applied by contact surface of abrasive particles and the workpiece, and resintering under high 
temperature and grinding load between abrasive grain and workpiece. Thus smooth compacted layers on the surface of scratches and grooves are formed; the other powdered crystalline grains flow away directly with flushing fluid. Powdering removal runs through the whole drilling process. Fig. (9) shows some powders.

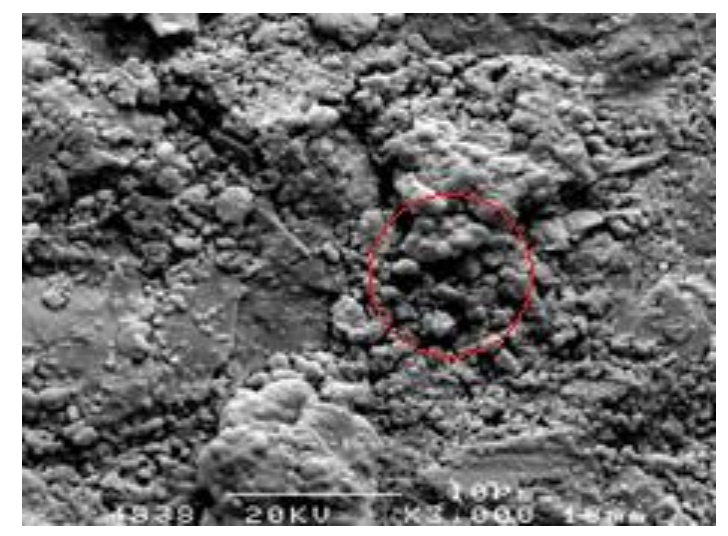

Fig. (9). Powdering of $\mathrm{SiC}$ ceramic.

\subsubsection{Effect of Spindle Speed and Axial Force on Drilling Morphology}

Spindle speed and axial force have effects on drilling morphology when examining the SEM photos. when spindle speed increases, more scratches are removed and develop into pits by the action of sharp abrasive particles, so the proportion of brittle fracture increases. However, when spindle speed increases a lot, diamond particles are worn fast and dull, the high temperature on the drilling surface will make recrystallization occur, then the proportion of pits decreases. When axial force increases gradually, the cutting depth of diamond particles increases, material is removed mostly in the form of brittle fracture, the proportion of pits increases; however overlarge axial force is apt to make diamond particles broken or even fall off, which reduce the cutting ability accordingly, so the proportion of scratches begins to rise, which means plastic deformation increases. However, in any case, brittle fracture is always dominant.

\subsubsection{Surface Damage}

Some manufacturing defects such as pores, glass phase and gaps can be found on the grain boundary through SEM observation, as shown in Fig. (10), these defects are the main causes of ceramic failure [26]. There are two reasons causing pores, glass phase and gaps. On one hand, the pores, glass phase and gaps are formed due to the immaturity of sintering process of $\mathrm{SiC}$ ceramics, so the $\mathrm{SiC}$ ceramics with $99.5 \mathrm{wt} \%$ were selected, the possibility of immaturity of sintering process is very small. On the other hand, pores, glass phase and gaps are formed in the grinding process of ceramic material.

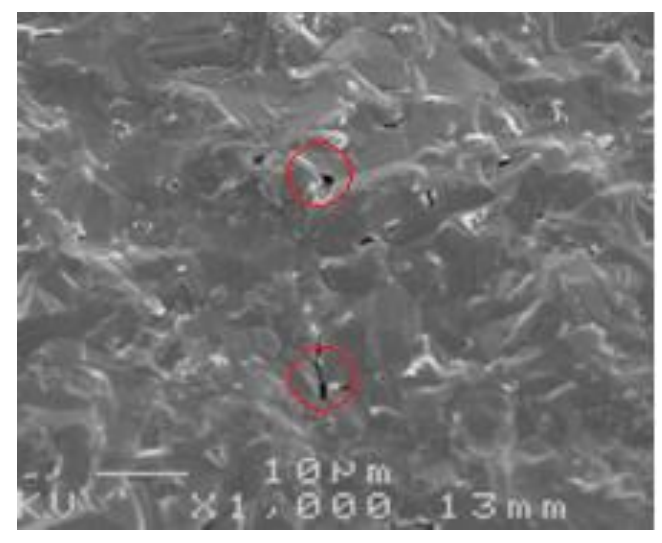

(a) $\times 1000$

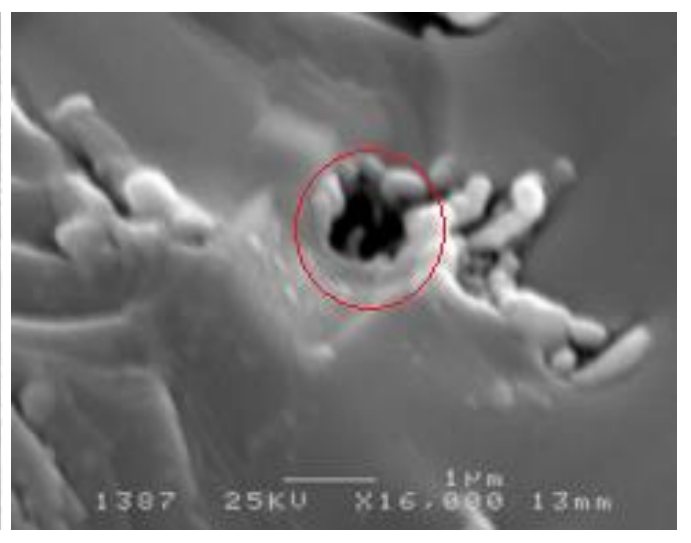

(b) $\times 16000$

Fig. (10). Pores on the drilling surface of SiC ceramic. 


\subsubsection{Damage to Pore Area}

The pores of $\mathrm{SiC}$ ceramics can be divided into the pores surrounded by grains and the pores in the grain. As shown in Fig. (10), for the pores in grains, internal porosity is usually much smaller than grain, which does not influence the strength and toughness of single grain, so the removal way of brittle fracture does not cause obvious processing damage such as residual cracks etc.. For the pores surrounded by grains, when abrasive particles cut across the stomatal periphery, the grains on the pore sides usually appear brittle fracture including cleavage fracture, transgranular fracture and intergranular fracture etc., and form disorder region composed by many narrow fracture surfaces and broken grains.

\subsubsection{Effect on Grain Boundary Area}

There also exist gaps and glass phases in the grain boundaries of $\mathrm{SiC}$ ceramics. SiC ceramics is apt to produce intergranular fracture under the action of grinding force due to the exist of grain boundary gap and relatively weak glass phase. However, the drilling process is of complexity, and the actual fracture ways also include cleavage fracture, transgranular fracture; there are obvious brittle pits on the edge of crystalline grains and the gap area, moreover, intergranular extension cracks can also be produced under the action of abrasive particles.

\subsubsection{Residual Cracks}

High stress concentration and high temperature are produced and make material appear fracture and deformation under the interaction of abrasive particles and ceramic. when the abrasives finish cutting in a moment, the ceramic materials will restore the deformation or form crackle or spalling, thus, the surface/sub surface crackles are formed, as shown in Fig. (11).

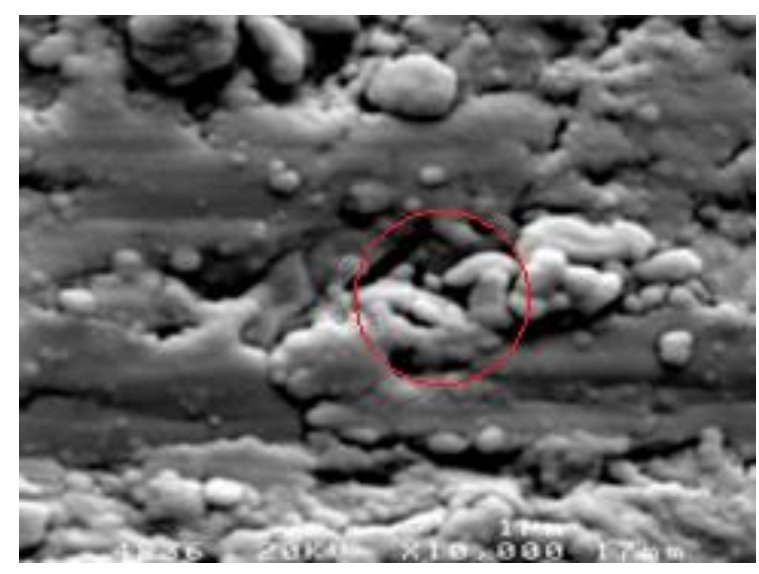

Fig. (11). Drilling cracks of $\mathrm{SiC}$ ceramic crystalline grains.

The reasons of generating cracks include two aspects: one is that transverse crack system and the central/radial crack system produced by the indentation fracture effect; the other is the residual stresses produced by temperature changes. Cracks are mainly divided into two categories, one is perpendicular to the drilling direction and the other is parallel to the drilling direction. The interruption of scratches and uneven distribution of cracks happen when crack propagations in two directions are connected. The block caving removal of ceramic material is easily caused by the crack propagation paralleling to the drilling direction on the edge of scratches.

\section{CONCLUSION}

1. The average cutting load and the minimum cutting depth of single abrasive are far greater than the critical cutting load and the critical cutting depth of $\mathrm{SiC}$ ceramic under experimental conditions, which indicate that brittle fracture is the dominant removal way for $\mathrm{SiC}$ ceramic.

2. SEM Photos show brittle fracture is the dominant characteristic, powdering and plastic deformation are also accompanied by the drilling process. Experimental results are consistent with the theoretical analysis.

3. Different spindle speed and axial force lead to proportions changing between brittle fracture and plastic deformation; brittle fracture is always dominant.

4. Cleavage fracture, transgranular fracture or intergranular fracture occur easily at intergranular pores and grain 
boundaries; residual cracks are formed in drilling surface by stress and high temperature

\section{ETHICS APPROVAL AND CONSENT TO PARTICIPATE}

Not applicable.

\section{CONSENT FOR PUBLICATION}

Not applicable.

\section{CONFLICT OF INTEREST}

The authors declare no conflict of interest, financial or otherwise.

\section{ACKNOWLEDGEMENTS}

This work was supported by the Natural Science Foundation of the Jiangsu Higher Education Institutions of China (Grant No.14KJB460008).

\section{REFERENCES}

[1] A. Afzaal, "Deposition and Analysis of Composite Coating on Aluminum Using Ti-B 4 C Powder Metallurgy Tools in EDM", Mater. Manuf. Process., vol. 31, no. 4, pp. 467-474, 2016. [http://dx.doi.org/10.1080/10426914.2015.1025967]

[2] M.R. Shabgard, and H. Alenabi, "Ultrasonic Assisted Electrical Discharge Machining of Ti-6Al-4V Alloy", Mater. Manuf. Process., vol. 30, no. 8, pp. 991-1000, 2016.

[http://dx.doi.org/10.1080/10426914.2015.1004686]

[3] M. Rehang, and P.K. Patowari, "Parametric Optimization for Selective Surface Modification in EDM Using Taguchi Analysis", Mater. Manuf. Process., vol. 31, no. 4, pp. 422-431, 2016. [http://dx.doi.org/10.1080/10426914.2015.1037921]

[4] L.F. Liu, F.H. Zhang, and H.M. Liu, "Ultrasonic Vibration Assisted Grinding of SiC Ceramic", Optics and Precision Engineering, vol. 23, no. 8, pp. 2229-2235, 2015.

[http://dx.doi.org/10.3788/OPE.20152308.2229]

[5] Y.T. Dai, D.S. Jiang, and S.Z. Da, "Ultra Precision Grinding of New Type Reactive Sintering SiC Ceramic", Zhongguo Jixie Gongcheng, vol. 17 , no. 6, pp. 595-597, 2006.

[6] Y.L. Zhang, Y.M. Zhang, J.C. Han, and W. Yao, "Grinding Parameter Optimization and Mechanism Research of Reactive Sintering SiC Ceramic", Materials Review, vol. 5, no. 21, pp. 233-236, 2007.

[7] X.J. Tang, X.L. Tian, Z.Y. Wu, J.F. Yang, and B.G. Zhang, "The Research and Progress of Fracture Behavior and Mechanism on the Edge of Engineering Ceramic", Zhongguo Jixie Gongcheng, vol. 21, no. 1, pp. 114-119, 2010.

[8] Z.B. Wang, C.F. Wang, and Z.M. Shan, "The Research of Numerical Control Grinding Technology on Engineering Ceramic", Academic Exchange, vol. 12, pp. 50-51, 2009.

[9] G.Z. Xie, H.W. Huang, H. Huang, X.M. Sheng, H.Q. Mi, and W.L. Xiong, "The Experimental Investigation of High Efficiency Deep Grinding on Engineering Ceramic Material", J. Mech. Eng., vol. 43, no. 1, pp. 176-184, 2007. [http://dx.doi.org/10.3901/JME.2007.01.176]

[10] J.X. Zheng, J.W. Xu, and Z.B. Lv, "Ductile Regime Grinding Mechanism of Ceramic Material", J. Chin. Ceram. Soc., vol. 34, no. 1, pp. 102-106, 2006.

[11] W. Yao, Y.M. Zhang, J.C. Han, and Y.F. Zhou, "Grinding Characteristics of Reactive Sintering SiC", J. Inorg. Mater., vol. 27, no. 7, pp. 764-768, 2012. [http://dx.doi.org/10.3724/SP.J.1077.2012.11514]

[12] J.M. Ni, and B.Z. Li, "Phase Transformation in high-speed Cylindrical Grinding of SiC and its Effects on Residual Stresses", Mater. Lett., vol. 89 , no. 15 , pp. $150-152,2012$.

[http://dx.doi.org/10.1016/j.matlet.2012.08.119]

[13] S. Agarwal, and P. Venkateswara Rao, "Experimental Investigation of Surface/Subsurface Damage Formation and Material Removal Mechanisms in SiC Grinding", Int. J. Mach. Tools Manuf., vol. 48, no. 6, pp. 698-710, 2007. [http://dx.doi.org/10.1016/j.ijmachtools.2007.10.013]

[14] R.J. Ji, Y.H. Liu, Y.Z. Zhang, H. Li, and X.D. Cheng, "Machining Performance and Surface Integrity of SiC Ceramic Machined Using Electrical Discharge Milling and the Mechanical Grinding Compound Process", Proc.- Inst. Mech. Eng., vol. 224, no. B10, pp. 1511-1518, 2010.

[http://dx.doi.org/10.1243/09544054JEM1863] 
[15] J.G. Cao, Y.B. Wu, J.Y. Li, and Q.J. Zhang, "Study on the Material Removal Process in Ultrasonic-assisted Grinding of SiC Ceramics Using Smooth Particle Hydrodynamic (SPH) Method", Int. J. Adv. Manuf. Technol., vol. 83, no. 5-8, pp. 985-994, 2016. [http://dx.doi.org/10.1007/s00170-015-7629-6]

[16] J. Xie, Q. Li, J.X. Sun, and Y.H. Li, "Study on Ductile-mode Mirror Grinding of SiC Ceramic Freeform Surface Using an Elliptical Torusshaped Diamond Wheel", J. Mater. Process. Technol., vol. 222, pp. 422-433, 2015. [http://dx.doi.org/10.1016/j.jmatprotec.2015.03.027]

[17] K. Zhang, H.H. Su, W. Xu, W. Huang, and J.H. Xu, "Influence of Plate Wheel Dressing of Monolayer Brazed Diamond Wheel on Material Removal Mechanism in SiC Grinding", J. Nanjing Univ. Aeronaut. Astronaut., vol. 46, no. 5, pp. 732-737, 2014.

[18] Y.J. Xie, X.H. Wang, X.Z. Hu, and X.Z. Zhu, "Fracture-based Model of Periodic-arrayed Indentation for Rock Cutting", J. Rock Mech. Min. Sci., vol. 76, pp. 217-221, 2015.

[http://dx.doi.org/10.1016/j.ijrmms.2015.03.018]

[19] F.L. Zhang, P. Liu, L.P. Nie, Y.M. Zhou, H.P. Huang, S.H. Wu, and H.T. Lin, "A Comparison on Core Drilling of Silicon Carbide and Alumina Engineering Ceramics with Mono-layer Brazed Diamond Tool Using Surfactant as Coolant", Ceram. Int., vol. 41, no. 7, pp. $8861-8867,2015$.

[http://dx.doi.org/10.1016/j.ceramint.2015.03.117]

[20] J. Gasc, Y.B. Wang, T. Yu, and I.C. Benea, "B. R. Rosczyk, T. Shinmei, T. Irifune. "High-pressure, High-temperature Plastic Deformation of Sintered Diamonds", Diam. Relat. Mater., vol. 59, pp. 95-103, 2015.

[http://dx.doi.org/10.1016/j.diamond.2015.09.001]

[21] S. Zhang, S. To, and G. Zhang, "Diamond Tool Wear in Ultra-precision Machining", Int. J. Adv. Manuf. Technol., vol. 88, no. 1-4, pp. 613-641, 2017. [http://dx.doi.org/10.1007/s00170-016-8751-9]

[22] M. Yahiaoui, J-Y. Paris, K. Delbé, J. Denape, L. Gerbaud, C. Colin, O. Ther, and A. Dourfaye, "Quality and Wear Behavior of Graded Polycrystalline Diamond Compact Cutters", Int. J. Refract. Met. H., vol. 56, pp. 87-95, 2016. [http://dx.doi.org/10.1016/j.ijrmhm.2015.12.009]

[23] S. Shukrullah, N.M. Mohamed, M.S. Shaharun, and M.Y. Naz, "Effect of Ethylene Flow Rate and CVD Process Time on Diameter Distribution of MWCNTs", Mater. Manuf. Process., vol. 31, no. 12, pp. 1537-1542, 2016. [http://dx.doi.org/10.1080/10426914.2015.1090588]

[24] S. Mandal, S. Kumar, P. Bhargava, C.H. Premsingh, C.P. Paul, and L.M. Kukreja, "An Experimental Investigation and Analysis of PTAW Process", Mater. Manuf. Process., vol. 30, no. 9, pp. 1131-1137, 2015. [http://dx.doi.org/10.1080/10426914.2014.984227]

[25] M.F. Chen, W.T. Hsiao, M.C. Wang, K.Y. Yang, and Y.F. Chen, "A Theoretical Analysis and Experimental Verification of a Laser Drilling Process for a Ceramic Substrate", Int. J. Adv. Manuf. Technol., vol. 81, no. 9-12, pp. 1723-1732, 2015. [http://dx.doi.org/10.1007/s00170-015-7219-7]

[26] A.K. Mainjot, A. Najjar, B.D. Jakubowicz-Kohen, and M.J. Sadoun, "Influence of Thermal Expansion Mismatch on Residual Stress Profile in Veneering Ceramic Layered on Zirconia: Measurement by Hole-drilling", Dent. Mater., vol. 31, no. 9, pp. 1142-1149, 2015. [http://dx.doi.org/10.1016/j.dental.2015.06.017]

\section{(C) $2017 \mathrm{Gao}$}

This is an open access article distributed under the terms of the Creative Commons Attribution 4.0 International Public License (CC-BY 4.0), a copy of which is available at: https://creativecommons.org/licenses/by/4.0/legalcode. This license permits unrestricted use, distribution, and reproduction in any medium, provided the original author and source are credited. 